\title{
Leaflet Surfaces of Blackspot-resistant and Susceptible Roses and Their Reactions to Fungal Invasion
}

\section{S. Reddy ${ }^{1}$, J.A. Spencer ${ }^{2}$ and S.E. Newman ${ }^{3}$ \\ Mississippi State University, Mississippi State, MS 39762}

Additional index words. Diplocarpon rosae, scanning electron microscopy, species roses, hybrid tea roses

\begin{abstract}
Leaflet surfaces of two blackspot (Diplocarpon rosae Wolf)-resistant roses (Rosa roxburghii Tratt and $R$. wichuraiana Crep.) and two susceptible roses ( $R$. hybrida 'Electron' and 'Pascali') were compared using scanning electron microscopy to determine whether physical features of the leaflet surface were associated with resistance to the fungal invasion. The leaflet surface features of the resistant roses were dissimilar: $\boldsymbol{R}$. roxburghii leaflet surface had protruding cells and was densely covered with amorphous wax platelets, whereas $R$. wichuraiana surface was smooth with less distinct epidermal cells and sparsely distributed wax granules. Leaflet surface patterns of both susceptible roses, however, were similar. The spores of $D$. rosae failed to germinate on $R$. roxburghii and $R$. wichuraiana. In contrast, the spores on 'Electron' and 'Pascal? germinated, with the germ tube penetrating the cuticle. There were no apparent morphological barriers on leaflet surfaces of $R$. roxburghii and $R$. wichuraiana to explain the observed resistance to fungal development.
\end{abstract}

Roses are among the most cherished of flowers in gardens and landscapes. In these outdoor roses, blackspot, caused by the fungus Diplocarpon rosae (Hasek, 1980), is a ubiquitous and devastating disease. The dis-

\footnotetext{
Received for publication 19 Mar. 1991. Accepted for publication 10 Sept. 1991. Mississippi Agricultural and Forestry Experiment Station article no. J-7841. This research project was supported in part by the Fred C. Gloeckner Foundation. The cost of publishing this paper was defrayed in part by the payment of page charges. Under postal reg ulations, this paper therefore must be hereby marked advertisement solely to indicate this fact.

'Dept. of Horticulture. Present address: Fisons Horticulture Inc., 177 Sanfordville Rd., Warwick, NY 10990.

${ }^{2}$ Dept. of Plant Pathology and Weed Science. ${ }^{3}$ Dept. of Horticulture.
}

ease can be recognized by irregularly shaped black spots, often surrounded by yellowing, on the upper surface of leaflets. With severe infection, the spots coalesce and the leaflet abscises prematurely.

Roses vary in susceptibility to blackspot. The widely cultivated hybrid tea and floribunda roses are susceptible, whereas other species of roses are more resistant (Castledine et al., 1981; Jenkins, 1955; Palmer et al., 1966). Although some species of roses may have resistance, they lack desired aesthetic traits.

Control of blackspot requires intensive chemical treatment. For example, at the American Rose Center gardens at Shreveport, La., fungicides are sprayed every week from February until November or December (Dobbs, 1984), i.e., as many as 40 sprays per year. Such use of fungicides is costly and potentially hazardous to people and the environment.

Most papers on blackspot have been concerned with the development of suitable methods for its control (Hagan et al., 1988). A few efforts to understand the physiology of disease resistance have also been made. These studies linked disease resistance to morphological characteristics of leaflets. For example, Dodge (1931) found that when the surface of 'Red Radiance' rose leaflet was rubbed or wounded with a needle, blackspot developed on this relatively resistant rose. Castledine et al. (1981) also noted blackspot infection in 'Pink Favorite' leaflets abraded with Carborundum powder but not in unabraded controls. These results show that undamaged, intact surfaces of leaflets present a barrier to blackspot infection in some roses. The researchers, however, did not examine the structure of leaflets to ascertain the morphological barriers inhibiting fungal development. Structure of a leaf can have an influence on fungal growth and thus on resistance to diseases (Juniper and Jeffree, 1983; Martin and Juniper, 1970; Royle, 1976).

The purpose of our study was to examine the fine structure of leaflet surfaces in some roses and determine whether any common features were associated with resistance or susceptibility to blackspot. Reactions of these rose leaflet surfaces to invasion by $D$. rosae were also examined to determine the stage of the fungus at which pathogenesis was arrested in resistant roses. Scanning electron microscopy (SEM) was used to obtain the fine structure.

Plant material. Spring growth of R osa roxburghii (also known as Chestnut rose) and $R$. wichuraiana and R. hybrida 'Electron' and 'Pascali', growing in the Rose Disease Research Garden, Mississippi State Univ. Farm, Starkville, were used as the source of leaflets. The two species of roses were observed to be naturally resistant, and the hybrid tea roses were susceptible to blackspot. 

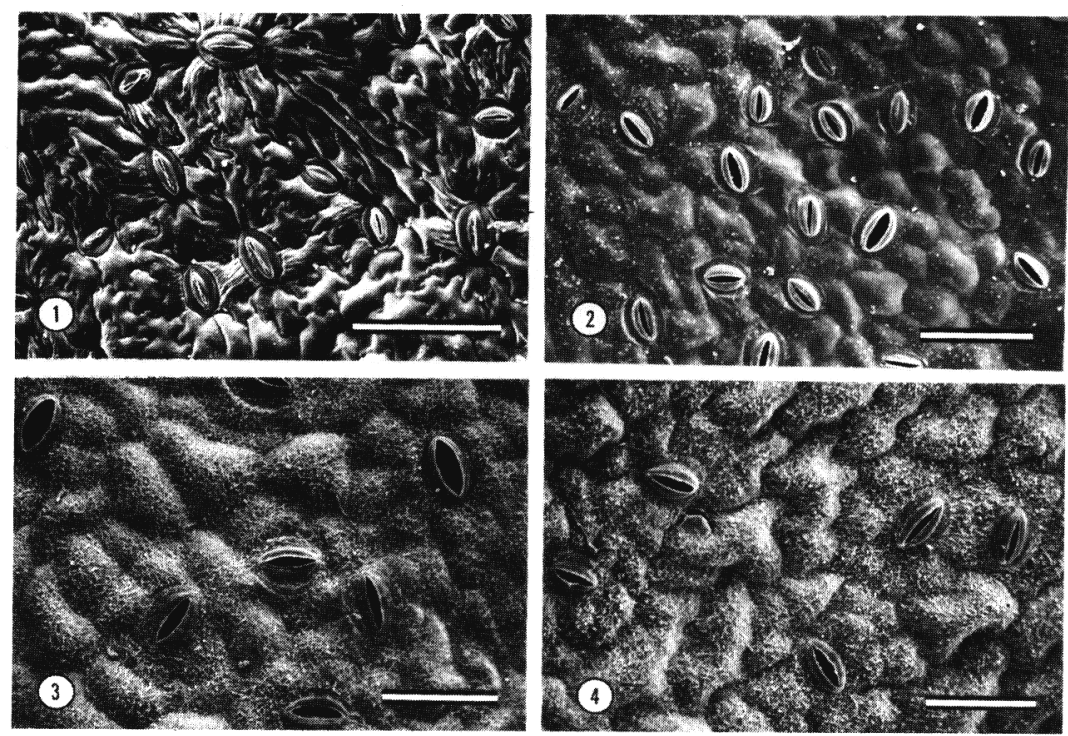

Figs. 1-4. Scanning electron micrographs of the abaxial surfaces of rose leaflets showing stomata. (1) Rosa roxburghii, (2) Rosa wichuraiana, (3) 'Electron', (4) 'Pascali'. Scale bar $=50 \mu \mathrm{m}$.
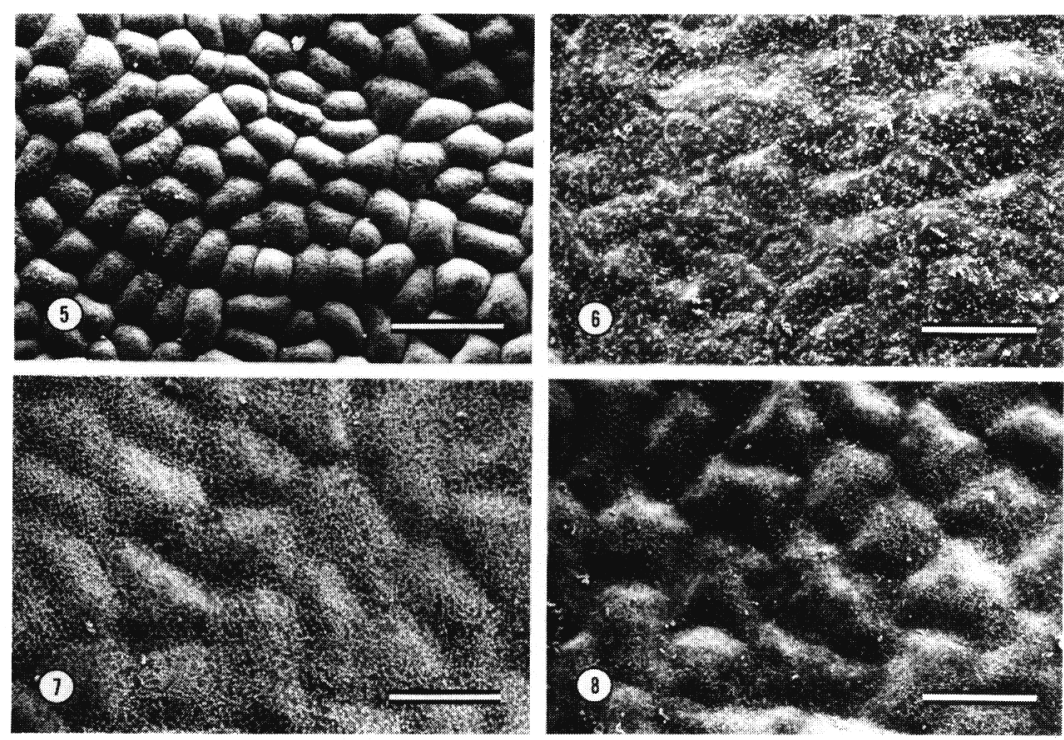

Figs. 5-8. Micrographs of the adaxial surfaces of rose leaflets. (5) Rosa roxburghii, (6) Rosa wichuraiana, (7) 'Electron', (8) 'Pascali'. Scale bar $=50 \mu \mathrm{m}$.

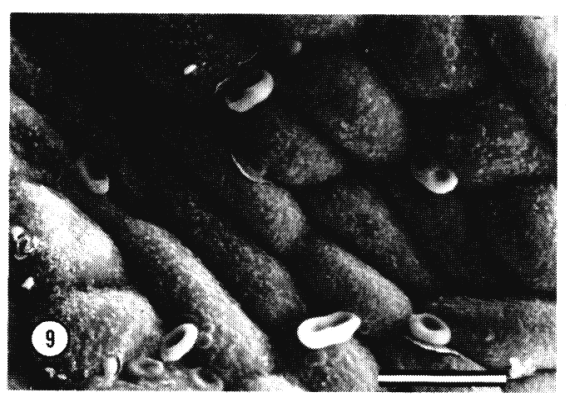

Fig. 9. Micrograph showing collapse of Diplocarpon rosae conidia on the resistant Rosa roxburghii leaflet surface 2 days postinoculation. Scale bar $=20 \mu \mathrm{m}$.

This response was substantiated in the laboratory by artificial inoculation with the fun- in susceptible roses. There was perfect correlation -between the detached leaflets and whole plants in disease resistance or susceptibility, indicating that this method was effective in comparing the response of roses to D. rosae. Leaflet samples were taken at 2 , 5,10 , and 14 days after inoculation and examined by SEM.

SEM. For SEM of uninoculated samples, leaflets were fixed in $2.5 \%$ glutaraldehyde in $0.05 \mathrm{M}$ potassium phosphate buffer, $\mathrm{pH}$ 7.1 , for at least $8 \mathrm{~h}$, changing the fixative at least once. Pieces, $5 \times 5 \mathrm{~mm}$ in area, were cut from leaflets and rinsed in $0.05 \mathrm{~m}$ phosphate buffer for 3 to $4 \mathrm{~h}$. These pieces were postfixed in $2 \% \mathrm{OsO}_{4}$ in $0.05 \mathrm{~m}$ phosphate buffer, $\mathrm{pH}$ 7.1, until tissue darkened (4 to 5 h). They were then rinsed in $0.05 \mathrm{M}$ phosphate buffer. The samples were dehydrated in a $35 \%, 50 \%, 70 \%, 95 \%$, and $100 \% \mathrm{EtOH}$ series for $25 \mathrm{~min}$ in each concentration and critical-point-dried (CPD) with $\mathrm{CO}_{2}$ in a Polaron E-3000 (Polaron, Watford, England). Dried samples were mounted on Al stubs with silver paste and sputter-coated with goldpalladium in a Polaron E5100. They were viewed with a JEOL-35CF (JEOL USA, Peabody, Mass.) microscope at $15 \mathrm{kV}$. Ctyo SEM was used to examine the rose $\times \mathbf{D}$. rosae interaction on inoculated leaflets so that fungal spores would not be dislodged and lost during the CPD preparation (which was used for the noninoculated samples). For cryo SEM, pieces were cut from the leaflet and mounted on a sample holder using a carbon medium.

The mounted sample was cooled by plunging it into liquid $\mathrm{N}_{2}$ slush and then transferred under vacuum to a preparation chamber. where it was sputter-coated with gold. The coated specimen was moved under vacuum to a cold stage in the specimen chamber of a JSM 840 microscope (JEOL USA) and examined at $15 \mathrm{kV}$ and -150 and - 180C. Many specimens were examined and only representative micrographs are shown.

A baxial surfaces. To establish infection, the fungus must gain entry into the leaflet either via natural openings, such as stomata, or through per\&ration of the intact surface. Stomata in all the roses examined were confined to the abaxial surface of leaflets (Figs. 1-4 vs. 5-8). Blackspot infection in nature always occurs on the adaxial surface. Thus, observations indicate that $\mathbf{D}$. rosae does not enter via stomata. Consequently, intact structural features on the adaxial surface became important in considering blackspot infection.

Adaxial surjaces. When the fungus enters through the intact surface of a leaflet, physical features of wax deposits and cuticularized epidermis can influence invasion (Martin and Juniper, 1970; Royle, 1976). There was variation in these features on adaxial leaflet surfaces of the roses (Figs. 5-8). However, the features of resistant roses were dissimilar.

The leaflet surface of $\mathbf{R}$ roxburghii surface was unusual in that it had a highly convex surface. The epidermis was characterized by the occurrence of enlarged and protruding 


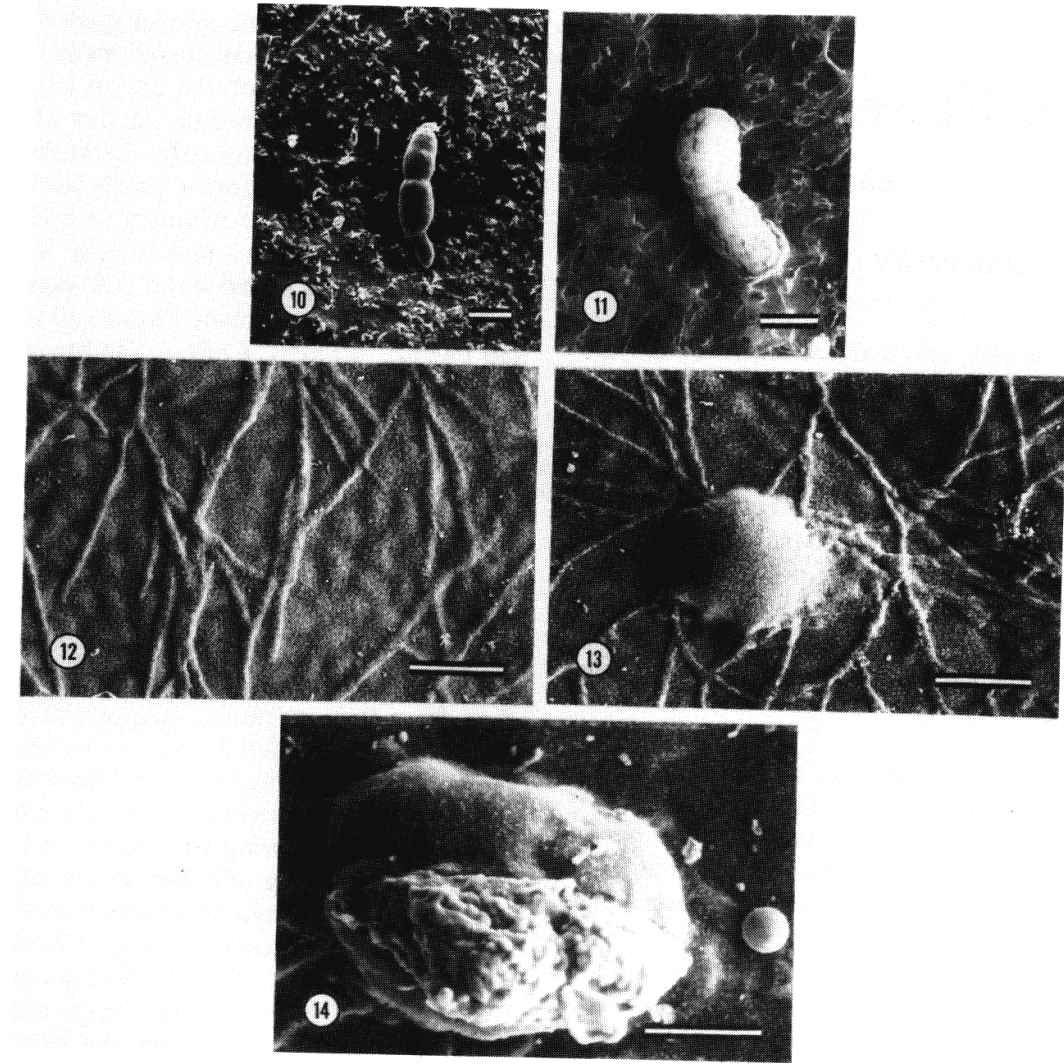

Figs. 10-14. Micrographs of Diplocarpon rosae development on the leaflet surfaces of susceptible 'Electron' rose at various times after inoculation. (10) Germination of conidium 2 days after inoculation. (11) Penetration of leaflet surface from the germ tube 2 days after inoculation. (12) Subcutitular hyphal strands 5 days after inoculation. (13) An unopened acervulus 10 days after inoculation (14) An opened acervulus containing conidia 14 days after inoculation. Scale bar $=5 \mu \mathrm{m}(\mathbf{1 0}, \mathbf{1 1})$; $100 \mu \mathrm{m}(\mathbf{1 2}, \mathbf{1 3}), 40 \mu \mathrm{m}(\mathbf{1 4})$.

cells (Fig. 5). This pattern was similar to the idioblast type of epidermis in the family Mesembryanthemaceae (Ihlenfeldt and Hartmann, 1982). The leaflet surface was covered by amorphous wax platelets.

In $R$. wichuraiana, the epidermis was smoother, without well-defined epidermal cells (Fig. 6). The anticlinal walls were indistinct. The outer walls of epidermal cells were only slightly domed. The wax was granular and sparsely distributed.

'Electron' (Fig. 7) and 'Pascali' (Fig. 8) leaflet surfaces were similar. The epidermal cells were distinct and had undulate anticlinal walls. The surface was covered by fine, tiny threads that fused to form a homogeneous net-like structure, which was dense on 'Electron' and sparse on 'Pascali'.

Thus, there were no common structural features on the leaflet surfaces that could be related to blackspot resistance. Therefore interactions between the leaflet surfaces ad the fungus were studied to find out how the resistant roses resist the pathogen's development.

Leaflet surface-pathogen interactions. Several stages of fungal growth, i.e., spore germination, germ tube growth, preparation for penetration, and penetration followed by hyphal growth, are needed for successful infection. Any of these stages could conceivably be halted by the host (Wyn and Staples, tion stage. The same type of reaction occurred in both resistant roses, suggesting a similarity between these roses in the way they reacted to fungal invasion. However, the observations revealed no structural barriers on resistant roses that could be associated with cessation of spore germination.

Since susceptible 'Electron' and 'Pascali' leaflet surfaces showed some similarity, one might assume that these roses provide stimuli for spore germination. However, since D. rosae spores germinate in the absence of a host, in water, or on agar (Dodge, 1931; Saunders, 1967), host stimuli obviously are not required for $D$. rosae spore germination. Thus, presence of spore germination inhibitors on resistant roses becomes a possibility, just as on some other plants (Kolattukudy and Koller, 1983; Martin and Juniper, 1970). However, the resistance to blackspot in some rose genotypes may also be related to physical barriers, as has been suggested for leaflets of some roses (Castledine et al., 1981; Dodge, 1931).

\section{Literature Cited}

Castledine, P., B.W.W. Grout, and A.V. Roberts. 1981. Cuticular resistance to Diplocarpon rosae. Trans. Brit. Mycol. Soc. 77:665-666.

Dobbs, R.B. 1984. Research battles blackspot in roses. Amer. Rose Annu. 69:44-54.

Dodge, R.B. 1931. A further study of the morphology and life history of the rose black spot fungus. Mycologia 23:446-462.

Hagan: A.K.; C.H. Gilliam and D.C. Fare. 1988. Evaluation of new fungicides for control of rose blackspot. J. Environ. Hort. 6:67-69.

Hasek, R.F. 1980. Roses, p. 81-105. In: R.A. Larson (ed.). Introduction to floriculture. Academic, New York

Ihlenfeldt, H.-D. and H.E.K. Hartman. 1981. Leaf surfaces in Mesembryanthemaceae, p. 397-423. In: D.F. Cutler, K.L. Alvin, and C.E. Price (eds.). The plant cuticle. Academic, New York.

Jenkins, W.R. 1955. Variability of pathogenicity and physiology of Diplocarpon rosae Wolf, the rose blackspot fungus. Amer. Rose Annu. 40:9297.

Juniper, B.E. and C.E. Jeffree. 1983. Plant surfaces. Edward Arnold, London.

Kolattukudy, P.E. and W. Keller. 1983. Fungal penetration of the first line of defensive barriers of plants, p. 79-100. In: J.A. Calow (ed.). Biochemical plant physiology. Wiley, Chichester, U.K.

Martin, J.T. and B.E. Juniper. 1970. The cuticles of plants. St. Martin Press. New York.

Palmer, J.G., P. Semeniuk, and R.N. Stewart. 1966. Roses and blackspot. I. Pathogenecity to excised leaflets of Diplocarpon rosae from seven geographic locations. Phytopathology 56:12771282 .

Royle, D.J. 1976. Structural features of resistance to plant diseases, p. 161-193. In: J. Friend and D.R. Threlafall (eds.). Biochemical aspects of plant-parasite relationships. Academic, New York.

Saunders, P.J.W. 1967. Host/parasite intersection in blackspot disease of roses caused by Diplocapon rosae Wolf. Annu. Applied Biol. 60:129136.

Wyn, W.K. and R.C. Staples. 1981. Tropisms of fungi in host recognition, p. 45-69. In: R.C. Staples and G.H. Toenniessen (eds.). Plant disease control. Wiley, New York. 